\title{
COMUNICAÇÃO NÃO-VERBAL DO PACIENTE EM CENTRO DE TERAPIA INTENSIVA CORONARIANA SUBMETIDO A INTUBAÇÃO OROTRAQUEAL: EFEITO DA PRESENÇA DA MÁQUINA*
}

Kátia Cilene Godinho Bertoncello**

Namie Okino Sawada***

\section{INTRODUÇÃO}

O estudo do paciente em centro de terapia intensiva coronariana submetido a intubação orotraqueal, exige uma metodologia específica, para retratar a linguagem corporal, isto é, a não-verbal, justificado pela afasia, ocasionada pela terapêutica empregada neste contexto.

SAWADA (1990) ao abordar a comunicação não-verbal a pacientes em pré-operatório, utilizou-se como instrumento metodológico a filmagem em vídeotape em cores, acoplado a um tripé móvel, para retratálos, o que possibilitou em síntese a evidência de que os enfermeiros não perceberam os sinais de tensão e ansiedade emitidos pelos pacientes, nesta fase.

Corroborando BOGDAN \& BIKLEN (1994) ao se tratar de assuntos interpessoais relacionados com a observação e registro visual, nunca consegue-se eliminar as conseqüências da presença da máquina, mas pode-se contar com elas quando concebe-se o plano de estudo.

Segundo D'AVILA NETO (1995) a utilização da imagem é uma nova via metodológica para a compreensão da vida cultural e social. Devido o vídeo tornar-se peça chave, no que diz a respeito a observação da linguagem gestual, registrando os três eixos dos comportamentos técnicos: o corporal, material e ritual.

\section{PRESSUPOSTOS DO EFEITO DA PRESENÇA DA MÁQUINA DE BOGDAN \& BIKLEN}

\author{
BOGDAN \& BIKLEN (1994) partem do
}

pressuposto que o efeito da presença da máquina pode ser (1) compensado, (2) explorado, (3) minimizado.

1. Compensado. Quando as pessoas têm consciência da presença da máquina fotográfica, os investigadores poderão utilizar a informação do modo como as pessoas modificam o seu comportamento em função desta presença para filtrarem a interpretação. Compensa-se a avaliação da sessão, tomando-se em consideração o fato de o fotógrafo ter estado presente.

2. Explorado. O efeito da presença de uma máquina fotográfica também pode ser explorado a desencadear informação sobre o "melhor" que os sujeitos têm ou querem mostrar. Sendo que o "melhor" não significa um julgamento absoluto, mas aquilo que os sujeitos valorizam e consideram digno de registrarse.

3. Minimizado. Se o estudo tiver como preocupação central as ocorrências típicas, terá de se encontrar uma forma de minimizar a distorção das rotinas causada pela presença do fotógrafo. O investigador tem que passar a ser, tanto quando possível, invisível. Há duas maneiras de se chegar a esse objetivo: através da familiaridade e da distração.

a) As pessoas acabam por acostumar-se e ficar indiferentes a qualquer coisa no seu meio ambiente, e o investigador não constitui exceção. Ao estar "sempre" presente e integrado, o fotógrafo acaba por deixar de ser um estímulo especial. Este tipo de indiferença pode instalar-se de uma forma incrivelmente rápida.

b) A segunda maneira de o investigador tornarse invisível é através da distração. Se houver atividades suficientemente interessantes no local, os sujeitos darão

\footnotetext{
* Notas da Dissertação de Mestrado apresentada, à Escola de Enfermagem de Ribeirão Preto da Universidade de São Paulo ** Enfermeira, Especialista em Pronto Socorro e Emergência, Professora Substituta da Universidade Federal de São Carlos, Mestranda na Área Fundamental, Escola de Enfermagem de Ribeirão Preto da Universidade de São Paulo

*** Enfermeira, Professor Doutor do Departamento de Enfermagem Geral e Especializada da Escola de Enfermagem de Ribeirão Preto da Universidade de São Paulo
} 
pouca atenção à máquina.

No retrato da importância da utilização desse instrumento como coleta de dados, os autores, expõe a seguinte frase de Stott, "se eu pudesse contar a história por palavras não teria tido necessidade de arrastar uma câmera fotográfica".

Fazem eco também da sugestão de Hine de que as imagens dizem mais do que as palavras, permitindo aos investigadores compreender e estudar aspectos da vida que não podem ser investigados através de outras abordagens e que necessitam de registro visual.

\section{CONSIDERAÇÕES FINAIS}

BOGDAN \& BIKLEN (1994) consideram importante, que o próprio investigador, registre os dados no campo, fornecendo imagens para uma inspeção intensa a posterior e que procure sinais, sobre as relações e as atividades desejadas do objeto de estudo.

\section{REFERÊNCIAS BIBLIOGRÁFICAS}

01. BOGDAN, R.C; BIKLEN, S.K. Investigação qualitativa em educação. Porto Editora, LTDA, 1994. p.183-93.

02. D'AVILA NETO, M.I. As representações do corpo feminino na sociedade brasileira contemporânea. In: Psicologia \& Práticas Sociais. Instituto de Psicologia da UERJ, v. 2, n. 1. 1994/1995. p. 91-8.
Durante a fase de análise, as revelações podem levar, para muito além do que teria sido esperado, como meio de lembrar e estudar detalhes que podem ser descurados com esta técnica utilizada para coleta de dados. Através do retrato das organizações, da aparência das pessoas, a disposição dos móveis, o conteúdo das prateleiras, entre outros, que passam a ter valor de história, devido ao registro de imagens realizadas.

BOGDAN \& BIKLEN (1994) finalizam com a colocação de que na procura dos investigadores educacionais, pela compreensão, através do registro de imagens, não são respostas, mas ferramentas que fornecem uma razão para juntar-se para discussão e assim chegar-se às respostas.

Diante do exposto, acredita-se que a técnica de filmagem em vídeo-tape, constitui-se poderosa ferramenta de coleta de dados, quando o assunto é analisar a comunicação não verbal. O investigador deve considerar os pressupostos de BOGDAN \& BIKLEN (1994) ao conceber o plano de estudo.

\section{SAWADA, N.O. Dimensão não verbal da} interação enfermeiro-paciente em situação pré-operatória. Ribeirão Preto, 1990. 97p. Dissertação (Mestrado) - Escola de Enfermagem de Ribeirão Preto, Universidade de São Paulo.

\section{PARTICIPACIÓN DE LA COMUNIDAD EN LA PROBLEMÁTICA DE SALUD. UN MODELO INTERDISCIPLINARIO DE INVESTIGACIÓN ACCIÓN}

\section{INTRODUCCION}

Las representaciones sociales de la participación comunitaria relacionadas con los problemas de salud de Villa Mercedes, sector del Municipio de Rosario de Lerma, en Salta Argentina, junto con el estudio sobre los contextos, la definición de la situación, la comprensión que le confieren a la acción los diferentes actores involucrados y la interacción para interpretar los procesos y los escenarios en los cuales actúan, constituyeron el eje central de este trabajo.

El interés surgió ante la observación de la ausencia de una verdadera participación de la comunidad en el área de la salud, elemento que al no estar presente condicionaba numerosas irregularidades en las diferentes etapas del proceso de promoción, prevención y protección de la salud.

* Lic.en Nutrición, Auxiliar de Investigación, Jefa de Trabajos Prácticos en Socioantropología

** Lic.en Servicio Social. Magister Scientiae en Metodología de la Investigación Científica y Técnica. Profesor Adjunto del Departamento de Salud Pública. Profesor en Desarrollo de la Comunidad y en Metodología de la Investigación Científica. Directora Proyecto de Investigación. Facultad de Ciencias de Salud. Universidad Nacional de Salta. Argentina 